\title{
The Aqueous Surface as an Efficient Transient Stop for the Reactivity of Gaseous $\mathrm{NO}_{2}$ in Liquid Water
}

\author{
Marilia T. C. Martins-Costa, ${ }^{\S}$ Josep M. Anglada, ${ }^{\dagger}$ Joseph S. Francisco ${ }^{\text {F }^{*}}$ and Manuel F. Ruiz-López ${ }^{{ }^{*}}$ \\ $\S^{\S}$ Laboratoire de Physique et Chimie Théoriques, UMR CNRS 7019, University of Lorraine, CNRS, BP 70239, 54506 Van- \\ doeuvre-lès-Nancy, France \\ ${ }^{\dagger}$ Departament de Química Biològica (IQAC - CSIC), c/ Jordi Girona 18, E-08034 Barcelona, Spain \\ Department of Earth and Environmental Science and Department of Chemistry, University of Pennsylvania, Philadelphia, \\ PA, USA 19104-6316
}

Supporting Information Placeholder

\begin{abstract}
The heterogeneous reaction of $\mathrm{NO}_{2}$ with water on diverse surfaces is broadly considered as a possible source of atmospheric HONO in dark conditions, but associated mechanisms are not fully understood. We report data from first-principles simulations showing that the lifetime of the putative reactive $\mathrm{NO}_{2}$ dimer on the surface of pure water droplets is too small to host the whole process. One infers from our results that the hydrolysis of $\mathrm{NO}_{2}$ in clouds must be catalyzed by organic or inorganics species adsorbed on the droplets.
\end{abstract}

Recently, the chemistry of $\mathrm{NO}_{2}$ on aqueous surfaces has attracted great attention. Photochemical processes in aqueous media have been studied both experimentally ${ }^{1-6}$ and theoretically, ${ }^{7-9}$ and simulations at the air-water interface ${ }^{10}$ have shown that they are a significant additional source of $\mathrm{OH}$ radicals in the troposphere. Many experimental studies have focused, however, on the thermal hydrolysis of $\mathrm{NO}_{2}$ (1), which has been studied for a long time. ${ }^{11-12}$ This key process produces HONO, whose photolysis (2) is a main source of tropospheric $\mathrm{OH}$, and nitric acid, related to acid rain.

$$
\begin{aligned}
& 2 \mathrm{NO}_{2}+\mathrm{H}_{2} \mathrm{O} \rightarrow \mathrm{HONO}+\mathrm{HNO}_{3} \\
& \mathrm{HONO}+\mathrm{hv} \rightarrow \mathrm{NO}+\mathrm{OH}
\end{aligned}
$$

The great interest generated by reaction (1) is principally due to the failure of current atmospheric models to predict observed concentrations of $\mathrm{HONO}$ and $\mathrm{OH}$, so that "unknown" sources of these species are suspected. Reaction (1) might represent one of such "unknown" sources for HONO ( $\mathrm{see}^{13-14}$ for a review on HONO sources).
Reaction (1) is not favorable in gas-phase, but according to experiments it is enhanced through $\mathrm{NO}_{2}$ adsorption on different surfaces, ${ }^{15-16}$ such as soot, mineral dust, soils, urban surfaces and foliage. The surface of water droplets may also participate to this chemistry, which is supported by field studies reporting the presence of HONO in aqueous aerosols and clouds. ${ }^{16}$ Though the reaction mechanism has not yet been completely elucidated, experiments on thin films supported by solid substrates ${ }^{16}$ suggested (Figure 1) that $\mathrm{NO}_{2}$ associates to form the symmetric dimer $\mathrm{O}_{2} \mathrm{~N}-\mathrm{NO}_{2}$. Upon adsorption on the surface, this dimer isomerizes to the less stable asymmetric dimer ONO-NO ${ }_{2}$, which ionizes to $\left(\mathrm{NO}^{+}\right)\left(\mathrm{NO}_{3}{ }^{-}\right)$stabilized by interactions with water. Finally, the charge separated species reacts with water to form $\mathrm{HONO}$, which desorbs to gas phase, and $\mathrm{HNO}_{3}$, assumed to remain at the surface in molecular or nitrate ion forms. ${ }^{17}$ The charge-separated dimer $\left(\mathrm{NO}^{+}\right)\left(\mathrm{NO}_{3}{ }^{-}\right)$is therefore considered as the reactive species for hydrolysis. It has also been proposed to be involved in the reaction of $\mathrm{NO}_{2}$ with $\mathrm{HCl}$ leading to $\mathrm{CINO} .{ }^{18-19}$

However, the mechanism of (1) is still unresolved and under discussion. ${ }^{13,20-22}$ One difficulty is the low gas phase concentration of $\mathrm{NO}_{2}$ and its low water solubility ( $H$ between $9.9 \times 10^{-5}$ and $4 \times 10^{-4} \mathrm{~mol} \cdot \mathrm{m}^{-3} \cdot \mathrm{Pa}^{-1}$ ), ${ }^{23}$ making the participation of dimers doubtful. ${ }^{24}$ Two observations can be made here. First, we have recently reported the free-energy of adsorption of $\mathrm{NO}_{2}$ at the interface $(-1.6$ $\left.\mathrm{kcal} \cdot \mathrm{mol}^{-1}\right)$, predicting an excess concentration by a factor of 10 with respect to gas phase. ${ }^{10}$ And second, $\mathrm{N}_{2} \mathrm{O}_{4}$ has a significant solubility in water $\left(H=1.4 \times 10^{-2}\right.$ $\left.\mathrm{mol} \cdot \mathrm{m}^{-3} \cdot \mathrm{Pa}^{-1}\right),{ }^{23}$ both factors advocating in favor of the mechanism described above. ${ }^{16}$ Experiments on aqueous microjets have shown that (1) is dramatically accelerated by anions, ${ }^{25}$ and the catalytic effect has been ascribed to $\mathrm{NO}_{2}$ uptake increase in their presence. ${ }^{24,26}$ 


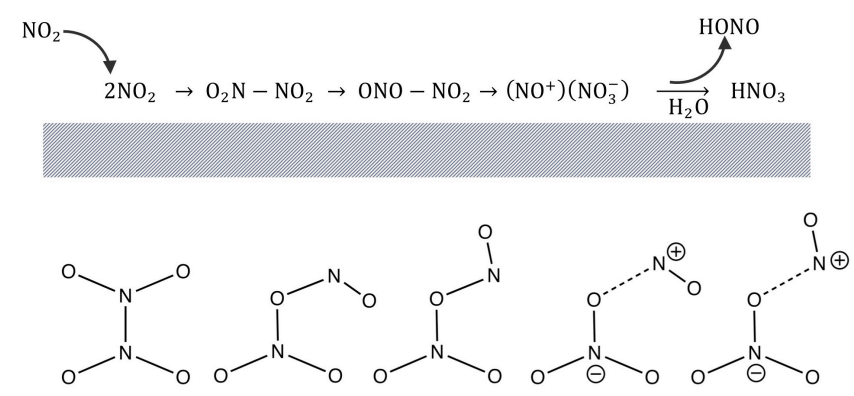

$\mathrm{O}_{2} \mathrm{~N}^{-\mathrm{NO}_{2}} \quad c$-ONO-NO $2 \quad t$-ONO-NO $\mathrm{NO}_{2} \quad c$ - $\left(\mathrm{NO}^{+}\right)\left(\mathrm{NO}_{3}^{-}\right) \quad t$-( $\left(\mathrm{NO}^{+}\right)\left(\mathrm{NO}_{3}^{-}\right)$

Figure 1. Schematic $\mathrm{NO}_{2}$ hydrolysis reaction on a surface and different structures of $\mathrm{NO}_{2}$ dimers.

Clarifying HONO formation mechanisms is therefore a pressing issue for improving current atmospheric models, and the hydrolysis of $\mathrm{NO}_{2}$ on the surface of liquid water is certainly one of the most important questions that remain to be addressed. To shed light on this topic, a number of theoretical studies in gas phase, ${ }^{27-28}$ water clusters, ${ }^{29-32}$ or bulk water, ${ }^{27}$ have been done using several methods. In general, these studies have confirmed the key role of $\left(\mathrm{NO}^{+}\right)\left(\mathrm{NO}_{3}^{-}\right)$in the mechanism described above. Moreover, it has been shown that the non-ionized asymmetric species $\mathrm{ONO}-\mathrm{NO}_{2}$, which has been experimentally detected ${ }^{33}$ and computationally described in the gas phase, ${ }^{34}$ is essentially unstable in water environments, spontaneously leading to $\left(\mathrm{NO}^{+}\right)\left(\mathrm{NO}_{3}{ }^{-}\right) \cdot{ }^{29}$ The formation of the dimer is the bottleneck of the whole process. ${ }^{35}$ It may proceed by direct $\mathrm{NO}_{2}$ dimerization, ${ }^{28,}$ 30 or by isomerization of the symmetric dimer $\mathrm{N}_{2} \mathrm{O}_{4}$ through a roaming-like transition state. ${ }^{35}$

To the best of our knowledge, only two theoretical studies have considered the $\left(\mathrm{NO}^{+}\right)\left(\mathrm{NO}_{3}{ }^{-}\right)$species on a realistic air-water interface model: Hammerich et $\mathrm{al}^{19}$ in a study of the $\mathrm{NO}_{2}+\mathrm{HCl}$ reaction, and $\mathrm{Li}$ et $\mathrm{al}^{36}$ in a study of the $\mathrm{NH}_{3}$-promoted hydrolysis reaction. In these works, ab initio molecular dynamics (MD) simulations (DFT level) were carried out on a water slab with periodic boundary conditions. However, owing to a high computational cost, the simulations were relatively short ( $\sim 20 \mathrm{ps})$, and this time scale may not be sufficient to understand all the complex dynamic behavior of the liquid water-vapor interface. ${ }^{37}$

Hereafter, we report important new findings about the aqueous chemistry of $\mathrm{NO}_{2}$ by carrying out QM/MM MD simulations approaching the nanosecond time scale (QM/MM stands for combined Quantum Mechanics and Molecular Mechanics potentials). The theoretical model has successfully been used to study other atmospheric $\mathrm{OH}$ sources,${ }^{38-39}$ and it is detailed in the Supporting Information (SI). Specifically, we describe the reactive $\mathrm{NO}_{2}$ asymmetric dimer at the quantum mechanical level (DFT) at the surface of a liquid water slab at $298 \mathrm{~K}$. The slab contains 499 flexible water molecules described classically; we assume periodic boundary conditions in the $\mathrm{XY}$ directions ( $\mathrm{Z}$ is the axis perpendicular to the interface). During equilibration, the $\mathrm{NO}_{2}$ dimer is forced to stay at the interface by constraining its Z-position. After equilibration, the Z-constraint is released, and the simulation is run for $300 \mathrm{ps}$. Since the dimer migrates to the bulk (see below), additional 300 ps are run after reequilibration assuming periodic boundary conditions in the XYZ directions.

The equilibration process at the interface is started with the covalent symmetric dimer $\mathrm{ONO}-\mathrm{NO}_{2}$. However, the later spontaneously reorganizes into $\left(\mathrm{NO}^{+}\right)\left(\mathrm{NO}_{3}{ }^{-}\right)$ at femtosecond time scale, and therefore it is this ionpair that is actually equilibrated and simulated. A similar fast reorganization process has been observed in small water clusters through ab initio MD simulations. ${ }^{29}$ When the Z-constraint is released after equilibration (Figure 2), the ion-pair initially stays at the interface for a few tens of picoseconds, deeply solvated in the inner water layer, but after $\sim 100 \mathrm{ps}$, the system migrates to bulk. The trend of $\left(\mathrm{NO}^{+}\right)\left(\mathrm{NO}_{3}{ }^{-}\right)$to spread into the bulk may be explained by extensive long-range electrostatic interactions with the solvent (due to a large charge separation in the solute, $0.63 \mathrm{e}$ on average) but also to the presence of strong hydrogen-bonds in the $\mathrm{NO}_{3}{ }^{-}$moiety (Figure $\mathrm{S} 2$ in the SI). The short residence time predicted for the reactive ion-pair at the interface ( $100 \mathrm{ps})$ has important consequences for the interfacial $\mathrm{NO}_{2}$ aqueous chemistry, as we discuss now.

To this purpose, it is pertinent to calculate the lifetime of $\left(\mathrm{NO}^{+}\right)\left(\mathrm{NO}_{3}^{-}\right)$in respect to its reaction with water. In principle, reaction lifetimes can directly be obtained from $a b$ initio simulations, but the computational cost becomes prohibitive for large activation barriers $\left(>>k_{B} \mathrm{~T}\right)$. Here, we obtain the reaction lifetime $\tau$ indirectly, using accurate thermodynamic data for the process to calculate the kinetic constant $\mathrm{k}$, so that $\tau=\mathrm{k}^{-1}$.

The energetics for the process:

$\left(\mathrm{NO}^{+}\right)\left(\mathrm{NO}_{3}^{-}\right)\left(\mathrm{H}_{2} \mathrm{O}\right)_{\mathrm{n}} \rightarrow(\mathrm{HONO})\left(\mathrm{HNO}_{3}\right)\left(\mathrm{H}_{2} \mathrm{O}\right)_{\mathrm{n}-1}$

has been studied in several works ${ }^{28,31-32,35}$ but accurate activation free-energies are not available. Li et $\mathrm{al}^{36}$ have reported values at DFT level lying between 5.6 and 8.2 $\mathrm{kcal} \cdot \mathrm{mol}^{-1}$, depending on cluster model. With the aim of determining more accurate kinetic data, we have carried out $\operatorname{CCSD}(\mathrm{T}) / 6-311+(3 \mathrm{df}, 2 \mathrm{p}) / / \mathrm{B} 3 \mathrm{LYP} / 6-311+\mathrm{G}(3 \mathrm{df}, 2 \mathrm{p})$ calculations for a cluster with two explicit water molecules immersed in a medium of variable dielectric constant. The contribution from tunneling effects has been calculated as well. The computational details and results are provided in the SI. When the system is in vacuum $(\varepsilon=1)$, the obtained barrier is $8.6 \mathrm{kcal} \cdot \mathrm{mol}^{-1}$, and the pseudo-first order kinetic constant is $\mathrm{k}=3.4 \times 10^{6} \mathrm{~s}^{-1}$ ( $\tau \sim 300 \mathrm{~ns}$ ). In bulk solution $(\varepsilon=78)$, the barrier lowers to $6.1 \mathrm{kcal} \cdot \mathrm{mol}^{-1}$, and $\mathrm{k}=2.4 \times 10^{8} \mathrm{~s}^{-1}(\tau \sim 4 \mathrm{~ns})$. At the interface, the kinetics is probably intermediate; one can esti- 
mate it using the dielectric constant of a low-polar solvent $(\varepsilon=3) .{ }^{40-43}$ One gets $7.1 \mathrm{kcal} \cdot \mathrm{mol}^{-1}$, and $\mathrm{k}=5.2 \times 10^{7} \mathrm{~s}^{-}$ ${ }^{1}(\tau \sim 20 \mathrm{~ns})$. From these values, it is found that the dimer lifetime is much larger than the (very short) interfacial residence lifetime, and accordingly, hydrolysis is more likely to occur in bulk. Only when a catalyst such as $\mathrm{NH}_{3}$ is present, ${ }^{36}$ the free energy barrier is significantly lowered (between 0.5 and $3.4 \mathrm{kcal} \mathrm{mol}^{-1}$, depending on model), and the corresponding half lifetimes (0.4-50 ps) becomes closer to the residence lifetime of the reactive species at the interface.

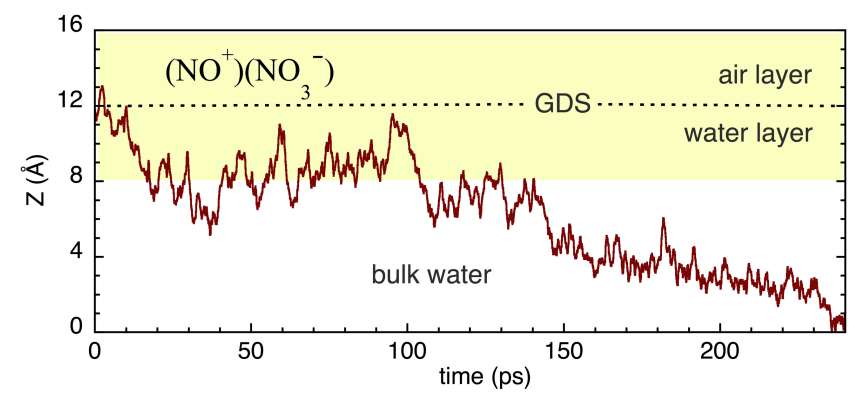

Figure 2. Center of mass position of $\left(\mathrm{NO}^{+}\right)\left(\mathrm{NO}_{3}^{-}\right)$along the QM/MM MD simulation at the air-water interface. The horizontal dashed line represents the Gibbs dividing surface. The thickness considered for the interface (yellow background) is based on the water density profile shown in Figure S1 in the SI.

Simulations at the interface and in bulk also show that the contact ion-pair $\left(\mathrm{NO}^{+}\right)\left(\mathrm{NO}_{3}{ }^{-}\right)$is quite stable. The two ions remain in direct contact with one short $\mathrm{N} \cdots \mathrm{O}$ distance fluctuating around $1.98 \AA$, and no ion dissociation, formation of solvent-separated ion pair structures, or dissociation into $\mathrm{NO}_{2}$ monomers is observed. Nevertheless, despite a high stability, the dimer displays a huge internal mobility of the charged moieties, with fast dynamical exchange between cis- and trans- configurations, and frequent jumps of the $\left(\mathrm{NO}^{+}\right)$cation to adjacent oxygen atoms in the anionic $\left(\mathrm{NO}_{3}^{-}\right)$moiety. The mechanism for these jumps is illustrated in Figure 3. They occur mainly between $\mathrm{O}$ atoms that are pointing towards the $\left(\mathrm{NO}^{+}\right)$direction $(\mathrm{O} 2$ and $\mathrm{O} 5$ in Figure 3). Jumps to the third oxygen atom (O6 in Figure 3) are much less frequent (it has been observed only once in our simulation). From probability histograms (see Figure S3 in the $\mathrm{SI}$ ), we estimate the free energy barriers for these processes to $3.2 \mathrm{kcal} \cdot \mathrm{mol}^{-1}$ (cis-trans conformational change) and $0.8 \mathrm{kcal} \cdot \mathrm{mol}^{-1}$ (jump to an adjacent $\mathrm{O}$ atom). For comparison, in the gas phase, the corresponding values are 2.8 and $5.1 \mathrm{kcal} \cdot \mathrm{mol}^{-1}$ for the non-ionized form of the asymmetric dimer, ${ }^{34}$ showing that the solvation effect on the O-exchange is quite large, as expected (though part of the effects has to be ascribed to the use of different quantum mechanical methods). The trans conformation is predicted to be more stable than the cis one by approximately $0.9 \mathrm{kcal} \mathrm{mol}^{-1}$ in bulk solution.
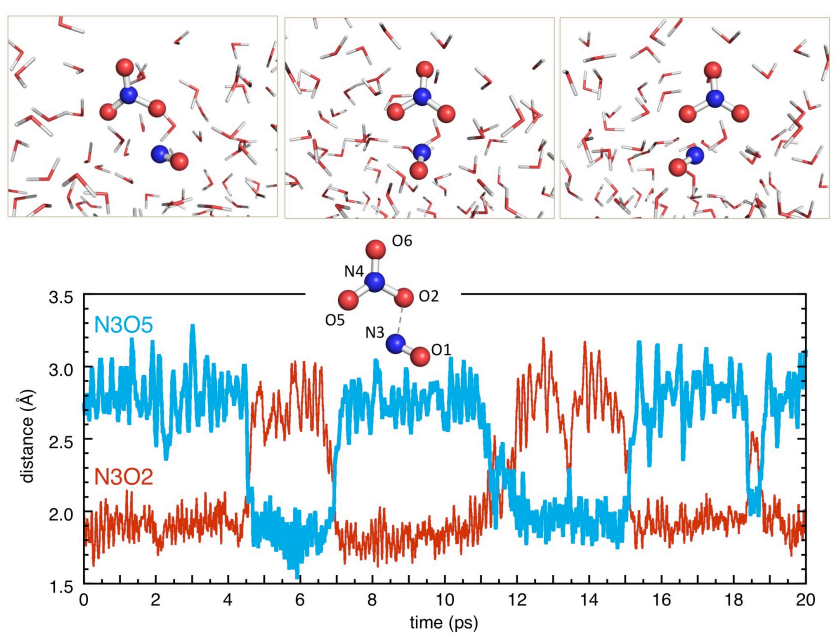

Figure 3. $\mathrm{QM} / \mathrm{MM}$ MD simulation of $\left(\mathrm{NO}^{+}\right)\left(\mathrm{NO}_{3}{ }^{-}\right)$at the air-water interface. The bottom panel illustrates the jumps of the $\mathrm{NO}^{+}$moiety between the $\mathrm{O} 2$ and $\mathrm{O} 5$ atoms of the $\mathrm{NO}_{3}{ }^{-}$moiety along the first $20 \mathrm{ps}$ of the simulation. The upper panel shows three snapshots for the first jump. The central snapshot corresponds roughly to the transition structure for which $\mathrm{N} 3 \mathrm{O} 2$ and $\mathrm{N} 3 \mathrm{O} 5$ distances are equal. The left and right snapshots correspond to $-600 \mathrm{fs}$ and $+600 \mathrm{fs}$ with respect to the middle snapshot, respectively.

In summary, the new data reported here help progress further understanding of the aqueous chemistry of $\mathrm{NO}_{2}$. Dimerization to form a reactive ion-pair is the first-step and bottleneck in the hydrolysis process, ${ }^{35}$ owing to significant interface affinity of $\mathrm{NO}_{2},{ }^{10}$ dimerization is likely to occur at the surface of water microdroplets. Reaction of the ion-pair with water is the subsequent step. Despite it is a fast reaction $\left(\mathrm{k} \sim 10^{7}-10^{8} \mathrm{~s}^{-1}\right)$, we have shown that the residence time of the ion-pair at the airwater interface $(\sim 100 \mathrm{ps})$ is too short for the reaction to occur there.

This result contrasts with the surface-enhanced processes reported for different solid surfaces, where HONO escapes to the gas phase and thus contributes to the atmospheric budget of $\mathrm{OH}$ through photolysis in daylight hours. On the contrary, in the droplet scenario, HONO appears to form preferably in the bulk rather than on the surface, therefore having little chance of escaping into the gas phase. The chemistry of HONO in bulk water encompasses a complex set of coupled reactions, including acid dissociation $\left(\mathrm{pK}_{\mathrm{a}}=3.16\right),{ }^{44}$ disproportionation, and photolysis, which yield nitric oxide and nitrate as main final products. Process (1) also yields the strong acid $\mathrm{HNO}_{3}$, which in aqueous solution dissociates to nitrate $\left(\mathrm{pK}_{\mathrm{a}}=-1.38\right)$ and contributes to acidify the medium, contrasting again with hydrolysis in thin films on solid surfaces. In the latter case, nitric acid is at least partially undissociated ${ }^{17}$ and produces $\mathrm{OH}$ radicals by direct photolysis in daytime $\left(\mathrm{ref}^{39}\right.$ and references 
cited therein). In future theoretical studies, modeling the chemistry of the ion-pair on water films as a function of the film thickness and the nature of the support will be most valuable and we are currently working in this direction.

Nonetheless, aerosols and water droplets are not pure water environments but contain species that may play a catalytic role on $\mathrm{NO}_{2}$ hydrolysis in nighttime. Some interfacial catalytic mechanisms have been described, with electrolytes ${ }^{24}$ or ammonia ${ }^{36}$ as catalysts, but other organic or inorganic compounds can be envisaged and future work needs to consider this possibility. This catalytic chemistry in nighttime together with photoenhanced reactions in daytime ${ }^{45-47}$ are plausible sources contributing to the yet unexplained excess concentrations of HONO found in the troposphere.

\section{ASSOCIATED CONTENT}

\section{Supporting Information}

Details on computational methods and Figures S1-S3 are provided as Supporting Information. The Supporting Information is available free of charge on the ACS Publications website.

\section{AUTHOR INFORMATION}

\section{Corresponding Author}

frjoseph@sas.upenn.edu (JSF)

manuel.ruiz@univ-lorraine.fr (MFRL)

\section{Funding Sources}

This project has been supported by the Generalitat de Catalunya (Grant No. 2017SGR348) and Spanish Ministerio de Economía y Competitividad (Project No. PID2019-109518GB-I00).

\section{ACKNOWLEDGMENT}

MMC and MFRL are grateful to the French CINES (project lct2550) for providing computational resources. JMA thanks the Catalan CSUC for providing computational resources.

\section{REFERENCES}

1. Crowley, J. N.; Carl, S. A. OH formation in the photoexcitation of $\mathrm{NO}_{2}$ beyond the dissociation threshold in the presence of water vapor. J. Phys. Chem. A 1997, 101, 4178-4184.

2. Li, S.; Matthews, J.; Sinha, A. Atmospheric hydroxyl radical production from electronically excited $\mathrm{NO}_{2}$ and $\mathrm{H}_{2} \mathrm{O}$. Science 2008, 319, 1657-1660.

3. Carr, S.; Heard, D. E.; Blitz, M. A. Comment on Atmospheric Hydroxyl Radical Production from Electronically Excited $\mathrm{NO}_{2}$ and $\mathrm{H}_{2} \mathrm{O}$. Science 2009, 324, 336.

4. Amedro, D.; Parker, A. E.; Schoemaecker, C.; Fittschen, C. Direct observation of $\mathrm{OH}$ radicals after $565 \mathrm{~nm}$ multi-photon excitation of $\mathrm{NO}_{2}$ in the presence of $\mathrm{H}_{2} \mathrm{O}$. Chem. Phys. Lett. 2011, $513,12-16$.
5. Li, S.; Matthews, J.; Sinha, A. Response to Comment on" Atmospheric Hydroxyl Radical Production from Electronically Excited $\mathrm{NO}_{2}$ and $\mathrm{H}_{2} \mathrm{O}$. Science 2009, 324, 336-336.

6. Dillon, T. J.; Crowley, J. N. Reactive quenching of electronically excited $\mathrm{NO}_{2}{ }^{*}$ and $\mathrm{NO}_{3}{ }^{*}$ by $\mathrm{H}_{2} \mathrm{O}$ as potential sources of atmospheric $\mathrm{HO}_{\mathrm{x}}$ radicals. Atmos. Chem. Phys. 2018, 18, 1400514015.

7. Minaev, B. F.; Zakharov, I. I.; Zakharova, O. I.; Tselishtev, A. B.; Filonchook, A. V.; Shevchenko, A. V. Photochemical Water Decomposition in the Troposphere: DFT Study with a Symmetrized Kohn-Sham Formalism. ChemPhysChem 2010, 11, 4028-4034.

8. Fang, Q.; Han, J.; Jiang, J.; Chen, X.; Fang, W. The conical intersection dominates the generation of tropospheric hydroxyl radicals from $\mathrm{NO}_{2}$ and $\mathrm{H}_{2}$ O. J. Phys. Chem. A 2010, 114, 4601-4608.

9. $\mathrm{Wu}, \mathrm{N}$.; Chen, X. Two photon dissociation dynamics of $\mathrm{NO}_{2}$ and $\mathrm{NO}_{2}+\mathrm{H}_{2} \mathrm{O}$. J. Phys. Chem. A 2012, 116, 6894-6900.

10. Martins-Costa, M. T. C.; Anglada, J. M.; Francisco, J. S.; Ruiz-Lopez, M. F. Theoretical Investigation of the Photoexcited $\mathrm{NO}_{2}+\mathrm{H}_{2} \mathrm{O}$ reaction at the Air-Water Interface and Its Atmospheric Implications. Chem. Eur. J. 2019, 25, 13899-13904.

11. Kameoka, Y.; Pigford, R. L. Absorption of Nitrogen Dioxide into Water, Sulfuric Acid, Sodium Hydroxide, and Alkaline Sodium Sulfite Aqueous Solutions. Ind. Eng. Chem. Fundam. 1977, 16, 163-169.

12. Sakamaki, F.; Hatakeyama, S.; Akimoto, H. Formation of nitrous acid and nitric oxide in the heterogeneous dark reaction of nitrogen dioxide and water vapor in a smog chamber. Int. J. Chem. Kinet. 1983, 15, 1013-1029.

13. Spataro, F.; Ianniello, A. Sources of atmospheric nitrous acid: State of the science, current research needs, and future prospects. J. Air Waste Manage. Assoc. 2014, 64, 1232-1250.

14. Lammel, G.; Cape, J. N. Nitrous acid and nitrite in the atmosphere. Chem. Soc. Rev. 1996, 25, 361-369.

15. Finlayson-Pitts, B. J.; Pitts, J. N. Chemistry of the upper and lower atmosphere: theory, experiments, and applications. Academic Press: San Diego, CA, 2000.

16. Finlayson-Pitts, B. J.; Wingen, L. M.; Sumner, A. L.; Syomin, D.; Ramazan, K. A. The heterogeneous hydrolysis of $\mathrm{NO}_{2}$ in laboratory systems and in outdoor and indoor atmospheres: An integrated mechanism. Phys. Chem. Chem. Phys. 2003, 5, 223-242.

17. Ramazan, K.; Wingen, L. M.; Miller, Y.; Chaban, G. M.; Gerber, R. B.; Xantheas, S. S.; Finlayson-Pitts, B. J. New experimental and theoretical approach to the heterogeneous hydrolysis of $\mathrm{NO}_{2}$ : key role of molecular nitric acid and its complexes. J. Phys. Chem. A 2006, 110, 6886-6897.

18. Raff, J. D.; Njegic, B.; Chang, W. L.; Gordon, M. S.; Dabdub, D.; Gerber, R. B.; Finlayson-Pitts, B. J. Chlorine activation indoors and outdoors via surface-mediated reactions of nitrogen oxides with hydrogen chloride. Proc. Natl. Acad. Sci. USA 2009, 106, 13647-13654.

19. Hammerich, A. D.; Finlayson-Pitts, B. J.; Gerber, R. B. $\mathrm{NO}_{\mathrm{x}}$ Reactions on Aqueous Surfaces with Gaseous $\mathrm{HCl}$ : Formation of a Potential Precursor to Atmospheric Cl Atoms. J. Phys. Chem. Lett. 2012, 3, 3405-3410.

20. Jenkin, M. E.; Cox, R. A.; Williams, D. J. Laboratory studies of the kinetics of formation of nitrous acid from the thermal reaction of nitrogen dioxide and water vapour. Atmos. Environ. 1988, $22,487-498$.

21. Gustafsson, R. J.; Kyriakou, G.; Lambert, R. M. The molecular mechanism of tropospheric nitrous acid production on mineral dust surfaces. ChemPhysChem 2008, 9, 1390-1393.

22. Ramazan, K. A.; Syomin, D.; Finlayson-Pitts, B. J. The photochemical production of $\mathrm{HONO}$ during the heterogeneous hydrolysis of $\mathrm{NO}_{2}$. Phys. Chem. Chem. Phys. 2004, 6, 3836-3843.

23. Sander, R. Compilation of Henry's law constants (version 4.0) for water as solvent. Atmos. Chem. Phys. 2015, 15, 4399-4981.

24. Colussi, A. J.; Enami, S.; Yabushita, A.; Hoffmann, M. R.; Liu, W.-G.; Mishra, H.; Goddard III, W. A. Tropospheric aerosol as a reactive intermediate. Faraday Discuss. 2013, 165, 407-420.

25. Kinugawa, T.; Enami, S.; Yabushita, A.; Kawasaki, M.; Hoffmann, M. R.; Colussi, A. J. Conversion of gaseous nitrogen 
dioxide to nitrate and nitrite on aqueous surfactants. Phys. Chem. Chem. Phys. 2011, 13, 5144-5149.

26. Colussi, A. J.; Enami, S. Detecting intermediates and products of fast heterogeneous reactions on liquid surfaces via online mass spectrometry. Atmosphere 2019, 10, 47.

27. Pimentel, A. S.; Lima, F. C. A.; da Silva, A. B. F. The isomerization of dinitrogen tetroxide: $\mathrm{O}_{2} \mathrm{~N}^{-\mathrm{NO}_{2}} \rightarrow-\mathrm{ONO}-\mathrm{NO}_{2} . J$. Phys. Chem. A 2007, 111, 2913-2920.

28. Zhu, R. S.; Lai, K.-Y.; Lin, M. C. Ab Initio Chemical Kinetics for the Hydrolysis of $\mathrm{N}_{2} \mathrm{O}_{4}$ Isomers in the Gas Phase. $J$. Phys. Chem. A 2012, 116, 4466-4472.

29. Miller, Y.; Finlayson-Pitts, B. J.; Gerber, R. B. Ionization of $\mathrm{N}_{2} \mathrm{O}_{4}$ in Contact with Water: Mechanism, Time Scales and Atmospheric Implications. J. Am. Chem. Soc. 2009, 131, 1218012185.

30. de Jesus Medeiros, D.; Pimentel, A. S. New Insights in the Atmospheric HONO Formation: New Pathways for $\mathrm{N}_{2} \mathrm{O}_{4}$ Isomerization and $\mathrm{NO}_{2}$ Dimerization in the Presence of Water. $J$. Phys. Chem. A 2011, 115, 6357-6365.

31. Luo, G.; Chen, X. Ground-State Intermolecular Proton Transfer of $\mathrm{N}_{2} \mathrm{O}_{4}$ and $\mathrm{H}_{2} \mathrm{O}$ : An Important Source of Atmospheric Hydroxyl Radical? J. Phys. Chem. Lett. 2012, 3, 1147-1153.

32. Varner, M. E.; Finlayson-Pitts, B. J.; Benny Gerber, R. Reaction of a charge-separated $\mathrm{ONONO}_{2}$ species with water in the formation of HONO: an MP2 Molecular Dynamics study. Phys. Chem. Chem. Phys. 2014, 16, 4483-4487.

33. Seifert, N. A.; Zaleski, D. P.; Fehnel, R.; Goswami, M.; Pate, B. H.; Lehmann, K. K.; Leung, H. O.; Marshall, M. D.; Stanton, J. F. The gas-phase structure of the asymmetric, trans-dinitrogen tetroxide $\left(\mathrm{N}_{2} \mathrm{O}_{4}\right)$, formed by dimerization of nitrogen dioxide $\left(\mathrm{NO}_{2}\right)$, from rotational spectroscopy and ab initio quantum chemistry. $J$. Chem. Phys. 2017, 146.

34. Liu, W.-G.; Goddard, W. A. First-Principles Study of the Role of Interconversion Between $\mathrm{NO}_{2}, \mathrm{~N}_{2} \mathrm{O}_{4}$, cis-ONO- $\mathrm{NO}_{2}$, and trans-ONO-NO ${ }_{2}$ in Chemical Processes. J. Am. Chem. Soc. 2012, 134 , 12970-12978.

35. Putikam, R.; Lin, M. C. A novel mechanism for the isomerization of $\mathrm{N}_{2} \mathrm{O}_{4}$ and its implication for the reaction with $\mathrm{H}_{2} \mathrm{O}$ and acid rain formation. Int. J. Quantum Chem. 2018, 118.

36. Li, L.; Duan, Z.; Li, H.; Zhu, C.; Henkelman, G.; Francisco, J. S.; Zeng, X. C. Formation of HONO from the $\mathrm{NH}_{3}$ promoted hydrolysis of $\mathrm{NO}_{2}$ dimers in the atmosphere. Proc. Natl. Acad. Sci. USA 2018, 115, 7236-7241.
37. Ruiz-Lopez, M. F.; Francisco, J. S.; Martins-Costa, M. T. C.; Anglada, J. M. Molecular reactions at aqueous interfaces. Nat. Rev. Chem. 2020, 4, 459-475.

38. Zhong, J.; Kumar, M.; Anglada, J. M.; Martins-Costa, M. T. C.; Ruiz-Lopez, M. F.; Zeng, X. C.; Francisco, J. S. Atmospheric Spectroscopy and Photochemistry at Environmental Water Interfaces. Annu. Rev. Phys. Chem. 2019, 70, 45-69.

39. Anglada, J. M.; Martins-Costa, M. T. C.; Francisco, J. S.; Ruiz-López, M. F. Photoinduced Oxidation Reactions at the AirWater Interface. J. Am. Chem. Soc. 2020, 142, 16140-16155.

40. Wang, H. F.; Borguet, E.; Eisenthal, K. B. Generalized interface polarity scale based on second harmonic spectroscopy. $J$. Phys. Chem. B 1998, 102, 4927-4932.

41. Wang, H. F.; Borguet, E.; Eisenthal, K. B. Polarity of liquid interfaces by second harmonic generation spectroscopy. $J$. Phys. Chem. A 1997, 101, 713-718.

42. Zimdars, D.; Eisenthal, K. B. Static and dynamic solvation at the air/water interface. J. Phys. Chem. B 2001, 105, 3993-4002.

43. Martins-Costa, M. C.; Ruiz-Lopez, M. Solvation effects on electronic polarization and reactivity indices at the air-water interface: insights from a theoretical study of cyanophenols. Theoret. Chem. Acc. 2015, 134, Art. N. 17.

44. Da Silva, G.; Kennedy, E. M.; Dlugogorski, B. Z. Ab initio procedure for aqueous-phase $\mathrm{pK}_{\mathrm{a}}$ calculation: the acidity of nitrous acid. J. Phys. Chem. A 2006, 110, 11371-11376.

45. George, C.; Strekowski, R.; Kleffmann, J.; Stemmler, K.; Ammann, M. Photoenhanced uptake of gaseous $\mathrm{NO}_{2}$ on solid organic compounds: a photochemical source of HONO? Faraday Discuss. 2005, 130, 195-210.

46. Liu, J. P.; Li, S.; Mekic, M.; Jiang, H. Y.; Zhou, W. T.; Loisel, G.; Song, W.; Wang, X. M.; Gligorovski, S. Photoenhanced Uptake of $\mathrm{NO}_{2}$ and HONO Formation on Real Urban Grime. Environ. Sci. Technol. Lett. 2019, 6, 413-417.

47. Wall, K. J.; Harris, G. W. Uptake of nitrogen dioxide $\left(\mathrm{NO}_{2}\right)$ on acidic aqueous humic acid (HA) solutions as a missing daytime nitrous acid (HONO) surface source. J. Atmos. Chem. 2017, 74, 283-321. 
Insert Table of Contents artwork here

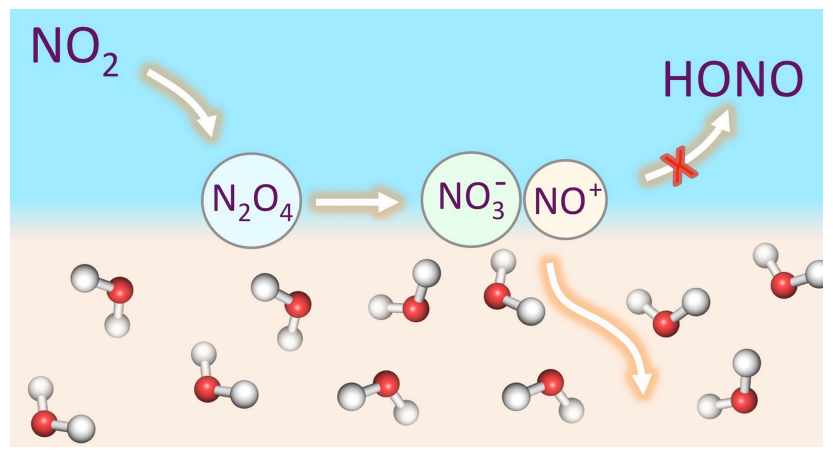

